Dossiê TEMÁTICo

HISTÓRIA SOCIAL, HISTÓRIA LOCAL/REGIONAL

\title{
MULHERES NAS LUTAS DE RESISTÊNCIA À DITADURA EMPRESARIAL-MILITAR NA BAHIA: PERSPECTIVAS NO ENSINO DE HISTÓRIA
}

\author{
WOMEN IN THE STRUGGLES OF RESISTANCE TO THE BUSINESS-MILITARY \\ DICTATORSHIP IN BAHIA: PERSPECTIVES IN HISTORY TEACHING
}

Daniela Rodrigues da Silva ${ }^{1}$

\begin{abstract}
RESUMO
Neste artigo, pretendemos analisar as trajetórias de mulheres nas lutas contrárias à Ditadura Empresarial-Militar, sob a ótica regional e local. Frequentemente ignoradas nas abordagens e nos materiais didático-pedagógicos do ensino de História sobre os espaços politicos e institucionais, as mulheres estão apagadas também nas narrativas sobre resistências e lutas. No sentido contrário a essa tendência, traçamos reflexões que contemplem a temática da participação desses sujeitos no combate ao governo ditatorial na Babia. No contexto da história local e regional, propomos algumas considerações sobre as políticas de preservação de memória e reparação do passado traumático a partir do estudo do monumento/ antimonumento "Aos 27 Baianos Mortos e Desaparecidos Políticos, Vitimas da Ditadura Militar", situado no município de Vitória da Conquista, cidade berço de duas mulheres que se lançaram nos embates contra a opressão ditatorial, Dinaelza Coqueiro e Diva Santana. Em tempos de questionamentos infundados do conhecimento científico com vistas ao revisionismo e negacionismo histórico, acreditamos que permitir a visibilidade, nas escolas, das histórias vividas por mulheres militantes é uma forma de resistir ao apagamento da memória nos campos de embates de disputas pela rememoração.
\end{abstract}

PALAVRAS-CHAVE: História regional. História local. Ditadura Empresarial-Militar. Mulheres. Ensino de História.

\begin{abstract}
In this article, we intend to analyze the trajectories of women in the struggles against the Business-Military Dictatorship, from a regional and local perspective. Often ignored in approaches and didactic-pedagogical materials of the teaching of History on political and institutional spaces, women are also erased in narratives about resistance and struggles. In the opposite direction to this tendency, we draw reflections that contemplate the theme of the participation of these subjects in the fight against the dictatorial government in Babia. In the context of local and regional history, we propose some considerations about the policies of memory preservation and repair of the traumatic past from the study of the monument/ antimonument Aos 27 Baianos Mortos e Desaparecidos Politicos, Victims of the Military Dictatorship, located in the municipality of $V$ itoria da Conquista, birthplace of two women who launched themselves in the struggles against dictatorial oppression, Dinaelza Coqueiro and Diva Santana. In times of unfounded questioning of scientific knowledge with a view to revisionism and historical negationism, we believe that allowing the visibility, in schools, of the stories lived by militant women is a way of resisting the erasure of memory in the battlefields of disputes for remembrance.
\end{abstract}

KEYWORDS: Regional history. Local history. Business-Military Dictatorship. Women. History Teaching.

\footnotetext{
${ }_{1}^{1}$ Professora da Rede Estadual de Ensino do Estado da Bahia. Mestre em Ensino de História pelo Mestrado Profissional em Ensino de História (ProfHistória) da Universidade Estadual do Sudoeste da Bahia (UESB). E-mail: danielarsilva6@gmail.com
} 
Que nada nos limite.

Que nada nos defina.

Que nada nos sujeite.

Que a liberdade seja nossa própria substância

(Simone de Beauvoir)

\section{INTRODUÇÃO}

O processo de ensinar e aprender História abrange muito mais do que um trabalho que visa à compreensão do conteúdo em si, pois na relação entre professor/a - estudante e nas dinâmicas empreendidas em sala de aula estão envolvidos indivíduos com uma gama de experiências, vivências e sentimentos. Incluir temáticas e conteúdos nas aulas de História que pretendam trazer reflexões aprofundadas sobre períodos e sujeitos históricos pouco tratados ou invisibilizados no currículo escolar, como as mulheres que lutaram contra a Ditadura Empresarial-Militar no Brasil, é fundamental para a prática de um ensino significativo para os/as estudantes.

Pouco ou quase nada é registrado sobre as mulheres na História. A historiografia, omissa à presença desses indivíduos nos acontecimentos históricos, reforça os discursos androcêntrico e machista, os quais propagam a inferioridade e subordinação da mulher que, em suas funções de procriar e cuidar do lar, deve viver recatada, calada, invisível aos olhos da sociedade. Os homens, que ocupam os espaços públicos, são os sujeitos privilegiados da história, únicos merecedores de ter suas ações e trajetórias perpetuadas nos relatos historiográficos. Se as mulheres não estão presentes na historiografia, consequentemente suas presenças também não são registradas nos livros e manuais didáticos utilizados pelos professores e alunos da Educação Básica.

Algumas motivações e justificativas podem ser apontadas para a ausência de mulheres nos registros da historiografia tradicional. Primeiramente, para que a mulher seja inserida nas páginas dos livros de História, é necessário reconhecer a sua força como sujeito histórico, assim como o homem. Em segundo lugar, o espaço doméstico é o ambiente destinado pela sociedade para o indivíduo feminino e, nesse espaço, de acordo com a ótica positivista, não acontecem fatos dignos de ser narrados na história. Ao longo da história, nem todas as mulheres obedeceram aos padrões sociais impostos. Desde sempre, é possível encontrar mulheres que subvertem a ordem, ocupando, ilegitimamente, lugares que não são considerados como seus. Mas, se a sociedade não as via com bons olhos, também a historiografia tradicional, votada a exaltar os papéis dos grandes governantes e os feitos dos heróis, as rejeita.

De acordo com Scott (1995, p. 86), "o gênero é um elemento constitutivo de relações sociais baseadas nas diferenças percebidas entre os sexos e é uma forma primária de dar significado às relações de poder". A escola, como espaço de poder, é um lugar de construção de relações de gênero. Com múltiplos sujeitos, ela é um espaço de práticas sociais e pedagógicas que criam, recriam, significam e ressignificam formas diversas de relações de poder. 
É necessário considerar que o/a estudante "não apenas reproduz os valores e os conhecimentos presentes no espaço escolar, como também produz valores e conhecimentos mediados pela sua cultura vivida" (GERMINARI, 2011, p. 194). No contexto de vivências, ensino e aprendizagens escolares, ocorre a constituição da "cultura da escola", confluência entre o movimento dialético dos saberes, metodologias, recursos escolares e a cultura dos sujeitos que integram o processo de escolarização (GERMINARI, 2011).

Em tempos de negacionismos e revisionismos, nos quais o conhecimento histórico é alvo de questionamentos infundados, trabalhar com temas considerados "polêmicos" é algo complexo e desafiador. Entretanto, a abordagem de temáticas como as que envolvem as mulheres nas lutas contra a ditadura sob a perspectiva da região em que os/as estudantes vivem, pode possibilitar a construção de "sentido" para aquilo que é ensinado, mediante a associação entre conteúdos propostos e as vivências práticas dos/as discentes. As ações voltadas para o conhecimento, reconhecimento, valorização e preservação dos objetos e lugares de memórias locais contribuem para a construção de um ensino de História que visa o desenvolvimento dos/as estudantes como sujeitos sociais, capazes de analisar e intervir criticamente no meio em que vivem.

O presente texto pretende apresentar propostas que resultem na retirada das mulheres da margem dos registros históricos, trazendo-as para o papel de protagonistas da história ensinada, enfatizando o ensino de História nas perspectivas regional e local.

\section{ELAS FORAM À LUTA: RESISTÊNCIA FEMININA À DITADURA EMPRESARIAL- MILITAR NO ENSINO DE HISTÓRIA}

No atual contexto, há uma exacerbação de disputas de memórias. As ondas de negacionismos e revisionismos, que estão em voga, tornam imperativo promover reflexões sobre o período ditatorial, que se instalou com o Golpe de 1964, mas, também, sobre a atuação de sujeitos que resistiram à repressão promovida pelos agentes ditatoriais. Mais além, pretende-se, aqui, evidenciar o papel das mulheres que lutaram contra o regime ditatorial e pela democracia.

Rita de Cássia Gonçalves (2018) ressalta a existência de um movimento crescente, protagonizado por estudantes e familiares que questionam a maneira como alguns conteúdos de História são abordados nas escolas. Especificamente sobre a Ditadura Empresarial-Militar, são muitos os questionamentos sobre as versões dos acontecimentos apresentadas pelo/a professor/a. Proliferam acusações de que, ao apresentar "sua história" dos eventos, o/a docente estaria incitando os/as estudantes a acatar determinada ideologia. Os autores destes questionamentos não consideram, entretanto, que a História é uma ciência, com metodologia própria de pesquisa e análise dos fatos históricos, sendo que só a verdade interessa ao/à historiador/a (VEYNE, 1998).

É, portanto, somente com a postura de enfrentamento que professores e professoras de História devem se pautar diante do trabalho em sala de aula com temáticas complexas, como as que envolvem gênero e ditadura. Tratar do período ditatorial é uma oportunidade para que os/as docentes possam 
incitar os/as discentes a argumentar sobre o que sabem e ouviram falar sobre o assunto, questionar determinados posicionamentos e confrontar opiniões com o conhecimento histórico. Como argumentam Gasparotto e Bauer (2021, p. 443), "para além da sensibilização que sua abordagem potencializa, as reflexões que oportunizam, justamente por sua complexidade, são fundamentais para a construção do conhecimento histórico".

Com o advento da corrente historiográfica voltada para a História das Mulheres, a partir de meados da segunda metade do século XX, e, posteriormente, com a problematização do termo "gênero", entendido como categoria de análise histórica, política e cultural, houve nas universidades a germinação do campo de estudos sobre a atuação das mulheres nos acontecimentos históricos. No entanto, a relação entre conhecimento acadêmico e a história ensinada nas escolas da Educação Básica é frequentemente mediada pelo uso do livro didático. Enquanto proliferam trabalhos acadêmicos que tratam sobre as mulheres na história, pautados pelos Estudos de Gênero, o resultado desses trabalhos não se refletem nos livros didáticos produzidos para atender o público escolar dos Ensinos Fundamental e Médio das escolas brasileiras (MACHADO, 2010).

Estudos realizados sobre a presença de mulheres nos conteúdos dos livros de História do Ensino Médio revelam que elas são muito pouco mencionadas. Em análise de uma coleção de manuais didáticos de uma determinada editora, Sanchez (2017) observa que os livros da $1^{\circ}$ a $3^{\circ}$ séries do Ensino Médio faz menção de 859 personagens históricos. Desse total, somente 70 mulheres. A pesquisa levou, ainda, à constatação de que os personagens femininos não têm papel de destaque. Elas são referenciadas, normalmente, em caixas de texto que ocupam pequeno espaço das páginas, à parte do eixo central da narrativa. Raramente essas mulheres são nomeadas. Quando há referências a feitos realizados por mulheres, não são colocados os seus nomes (SANCHEZ, 2017).

Os livros didáticos de História possuem, como uma de suas características, a simplificação do conhecimento histórico, já que pretendem fornecer aos/às discentes apenas uma visão global dos acontecimentos concernentes à história (FONSECA. 2009). As explicações reducionistas, entretanto, podem levar à generalização e omissão com relação a eventos e sujeitos, como afirma Selva Fonseca (2009, p. 53):

O processo de simplificação no âmbito da difusão implica tornar definitivas, institucionalizadas e legitimadas pela sociedade determinadas visões e explicações históricas. Essas representações transmitidas simplificadamente trazem consigo a marca da exclusão. [...] No livro didático o processo de exclusão de ações e sujeitos faz parte da lógica de didatização.

Em estudos sobre as mulheres e a Ditadura Empresarial-Militar nos livros de História do Ensino Médio, Vanderlei Machado (2010), examinou onze livros didáticos de distintos autores e editoras e concluiu que, desse número total, apenas três fazem referência às mulheres nas abordagens sobre a ditadura. Somente dois livros mencionam a participação de mulheres ou de organizações femininas nas lutas contra a repressão ditatorial. 
Os resultados dos estudos apresentados reforçam a constatação de que os livros didáticos corroboram com a visão preconceituosa de que as mulheres não devem ter atuação nos espaços públicos e reafirmam a concepção de que elas são predeterminadas a se ocupar de atividades relacionadas à maternidade e aos cuidados domésticos. Os livros didáticos e os currículos de História não são isentos de intencionalidades. Eles são objeto de escolhas, em relação a conteúdos e abordagens, pensados com a intenção de atender determinados propósitos. Destacam Silva e Fonseca (2010, p. 16-17):

\begin{abstract}
Pensar nos lugares, nos papéis, na importância formativa da História no currículo da Educação Básica requer concebê-la como conhecimento e prática social, em permanente (re) construção, um campo de lutas, um processo de inacabamento. Um currículo de História é, sempre, produto de escolhas, visões, interpretações, concepções de alguém ou de algum grupo que, em determinados espaços e tempos, detém o poder de dizer e fazer. Os currículos de História - sejam aqueles produtos das políticas públicas ou da indústria editorial, sejam os currículos construídos pelos professores na experiência cotidiana da sala de aula - expressam visões e escolhas, revelam tensões, conflitos, acordos, consensos, aproximações e distanciamentos.
\end{abstract}

Os currículos e as práticas de ensino de História inserem-se em um processo dialético de construção e reconstrução. Por essa razão se torna necessário incluir discussões, temas e problematizações que superem os conteúdos canônicos, geralmente apresentados nos programas da disciplina de História na Educação Básica.

Por outro lado, a ausência de discussões sobre questões de gênero nas aulas de História pode ser creditada ao fato de que os/as docentes, na maior parte das vezes, não tiveram, em suas formações, disciplinas acadêmicas que tratassem sobre as relações de gênero e/ou sobre História das Mulheres. Além disso, como salienta Zarbato (2015, p. 58), "na formação de professores/as, ao analisar a questão do gênero, os docentes, estão imbuídos de concepções culturais, que muitas vezes impede o diálogo com os outros". A essas circunstâncias vêm somar-se as limitações dos livros didáticos de história, que contribuem para reforçar a invisibilidade e subalternização das mulheres na abordagem de conteúdos escolares.

Carla Pinsky (2018) põe em destaque a constatação de que o/a estudante passa, muitas vezes, por toda a etapa da escolarização sem ter tido oportunidades de refletir sobre as relações de gênero nas aulas de História. Para a autora, essa lacuna provocada pela falta de abordagens relacionadas à construção social da diferença sexual é grave e indica que o trabalho com as questões de gênero pode enriquecer as abordagens nas aulas da disciplina História:

Capacitar os estudantes para perceber a historicidade de concepções, mentalidades, práticas e formas de relações sociais é justamente uma das principais funções das aulas de História. Ao observar que as ideias a respeito do que é "ser homem" e "ser mulher", os papéis considerados femininos e os masculinos ou a condição das mulheres, por exemplo, foram se transformando ao longo da história (como e por que), os alunos passam a ter uma visão mais crítica de suas próprias concepções, bem como das regras sociais e verdades apresentadas como absolutas e definitivas no que diz respeito às relações de gênero. Também adquirem uma compreensão maior dos limites e possibilidades dos seres históricos (os estudantes entre eles), pois dentro das determinações históricas também é possível fazer escolhas, mesmo em aspectos que, 
por sua aparente ligação com a biologia, se mostram difić́limos de serem mudados (e melhorados) (PINSKY, 2018, p. 32-33)

Ana Maria Colling (1997), em estudo pioneiros sobre a resistência feminina ao golpe de 1964 no Brasil, destaca que as mulheres que se envolveram nas lutas contra o governo ditatorial eram consideradas "sujeitos subversivos". A transgressão a elas atribuída foi sair dos limites das paredes domésticas e invadir espaços nos quais a sociedade, que estabelece relações de poder de acordo com as identidades de gênero, considera como unicamente masculinos:

Para a repressão, a mulher militante era encarada como inimiga por duas razões: por ser opositora ao regime militar e por ser mulher desviante. [...] O discurso da repressão, tanto através de documentos como através das memórias das mulheres, não é um discurso isolado. Este mesmo discurso está presente na sociedade, a repressão somente o recolhe e verbaliza (COLLING, 1997, p. 107-112)

As mulheres que ousaram participar das lutas contra a repressão ditatorial tiveram, portanto, que lidar com estereótipos de gênero que permeavam a mentalidade da sociedade, de forma geral, e dos agentes responsáveis pela prática da violência institucional, em particular. As mulheres consideradas "direitas", "de bem", dedicavam a vida aos cuidados da família, do lar. Quanto às militantes, por entender que elas não estavam cumprindo devidamente o seu papel enquanto filhas, esposas e mães, transgredindo as normas impostas e se lançando nos espaços públicos de luta, os militares as consideravam merecedoras de todas as humilhações, agressões e violações perpetradas por eles, no intuito de mostrar-lhes quais eram s seus devidos lugares na sociedade.

Em outra perspectiva de análise, Reis Filho e Ferreira de Sá (1985) ressaltam que os quadros dirigentes dos partidos da esquerda eram, em sua maioria, compostos por homens brancos e de classe média. Sobre a composição de gênero nas fileiras das agremiações comunistas, Marcelo Ridenti (1999) constatou que, no período de 1960-1970, as organizações armadas de esquerda contavam com cerca de $20 \%$ de mulheres entre seus integrantes. Muitas dessas mulheres tiveram experiências com prisões e torturas promovidas pelos órgãos de repressão, que utilizavam o terror "a fim de intimidar o inimigo (interno) e dissuadir os indecisos" (BORGES, 2014, p. 29).

A resistência feminina à ditadura não diz respeito somente às mulheres que participaram diretamente das organizações de esquerda. Aqui, a expressão "luta" também adquire um sentido amplo, que abrange várias circunstâncias, para além da luta armada. Além das militantes que pegaram em armas, temos que reconhecer a importância da luta de mães que lutaram por seus filhos e filhas, presos/as ou desaparecidos/as políticos/as, assim como de esposas lutaram por seus maridos, de filhas que lutaram por seus pais, de irmãs que lutaram por seus irmãos. Importante referenciar também as mulheres que se arriscaram auxiliando militantes, seja através de ajuda financeira, seja oferecendo abrigo; as que lutaram nas campanhas pela anistia; e aquelas que resistiram à repressão ao partir para o exílio e sofreram por deixar a família e o país para trás. Quantas mulheres simpatizaram com a causa e, por acreditar nos ideais disseminados pela esquerda, se envolveram afetuosamente e auxiliaram, mesmo que indiretamente, as 
organizações comunistas? Enfim, não há como mensurar a quantidade de mulheres que, de diversas maneiras, lutaram, resistindo à situação de extrema violência estatal em que o Brasil se encontrava.

Ao tomar como objeto de estudo as mulheres nas lutas contra o Estado ditatorial, procuramos destacar a importância das personagens femininas para o estabelecimento de uma história que abarque, sob a ótica dos oprimidos, as várias instâncias e circunstâncias nas quais o governo opressor atuou. Resgatar a atuação feminina na história da Ditadura Empresarial-Militar significa retirar as mulheres da penumbra da história, na perspectiva proposta por Valadares (apud JOFFILY, 2005, p. 10): "poder-se-ia dizer que a história da mulher na sociedade é a história da invisibilidade do visível. Ou da visibilidade do invisível".

\section{TEMPOS SOMBRIOS NA BAHIA}

Calil (2015) dedicou-se a estudar a disciplina História encontra-se preconizado nas diretrizes propostas para Base Nacional Comum Curricular (BNCC) para a área de Ciências Humanas e Sociais Aplicadas. ${ }^{2}$ Chegou à conclusão de que o projeto estava sendo elaborado "sob uma lente redutora que procura basicamente fazer comparações ou identificar suas consequências para a história brasileira" (CALIL, 2015, p. 41). Para o autor, predominava a concepção de uma história voltada para o patriotismo e desvinculada do estudo de conceitos importantes para a compreensão da realidade atual. Calil aponta para "uma forte individualização da História, [...] que enseja forte ênfase nos sujeitos individuais em detrimento das forças sociais" (CALIL, 2015, p. 46).

No atual contexto, marcado pela aprovação da nova BNCC, torna-se imperativo realizar abordagens associadas com as vivências dos/as estudantes e estabelecer relações entre os conteúdos históricos e a realidade social prática. Nesse processo, o ensino de História nas perspectivas do local e do regional adquire importância significativa.

A História Regional está além da localização geográfica que abrange uma região, um estado ou município, como salienta Martins (2018, p. 143).

A História Regional é a que vê o lugar, a região e o território como a natureza da
sociedade e da história, e não apenas como o palco imóvel onde a vida acontece. Ela
é História Econômica, Social, Demográfica, Cultural, Política etc., referida ao
conceito chave de região. Os temas e os problemas da História Regional são os
mesmos da História, sem tirar nem pôr. Na verdade, a História Regional constitui
uma abordagem específica, uma proposta de estudo da experiência de grupos sociais
historicamente vinculados a uma base territorial. Os "historiadores regionalistas"
trabalham com regiões e localidades não porque afirmam a dicotomia entre o geral e
o particular. Fazem isso porque questionam e criticam as narrativas e interpretações
históricas dominantes e as crônicas triunfalistas do progresso, seus pressupostos e
implicações político-identitárias.

\footnotetext{
2 A Base Nacional Comum Curricular é o principal documento norteador da educação no Brasil, na atualidade. A ideia de implantação de uma base nacional comum para a Educação Básica no Brasil está prevista desde a Constituição Federal de 1988 e na Lei de Diretrizes e Bases da Educação Nacional (LDB) de 1996. A construção da atual versão do Documento foi iniciada em 2015. Em 2017 foi aprovado o projeto relacionado ao Ensino Fundamental e, em 2018, o documento orientador para o Ensino Médio.
} 
A abordagem de temáticas relacionadas à Ditadura Empresarial-Militar, seja nas perspectivas nacional, regional ou local, pode gerar controvérsias, justamente por se tratar de uma história inserida no contexto do tempo presente. O golpe de 1964 e seus desdobramentos são alvos de disputas de memórias e opiniões e as polêmicas geradas podem resultar em recuo do/a professor/a.

Alessandra Gasparotto e Caroline Bauer (2021) apresentaram algumas razões para que o período ditatorial seja incorporado ao conteúdo das aulas de história nas escolas. Primeiramente, porque "circulam no espaço escolar fragmentos dessas memórias, opiniões diversas e uma série de noções cristalizadas acerca desse passado, [...] que tendem a relativizar a lógica e a violência ditatorial. [....]” Há que se considerar também que "muitos [livros didáticos] continuam reproduzindo [...] uma abordagem linear e cronológica, [...] que enfatiza o binômio repressão e resistência, desvinculada de uma discussão mais ampla". Enfim, as autoras ressaltam o "alcance limitado das políticas de memória sobre a ditadura no Brasil (e sua efetivação tardia) contribuiu para que o tema fosse marcado pelo silêncio e pelo esquecimento" (GASPAROTTO; BAUER, 2021, p. 444).

O Brasil vivenciou tempos sombrios, desde a deflagração do golpe que instaurou a Ditadura Empresarial-Militar, em 1964. O período foi marcado pela ascensão do autoritarismo estatal, pelo cerceamento de direitos e pela intensa repressão. Na concepção dos militares, o país precisava de uma intervenção "revolucionária" com o intuito de manter a ordem, livrando a nação das "garras" dos comunistas. Bem articulado, o regime ditatorial manteve-se, pela força, durante longos 21 anos.

O golpe de Estado foi habilmente arquitetado por militares, em articulação com civis, nomeadamente empresários do mercado nacional e internacional. Entendemos, então, que o Brasil viveu, no período de 1964 a 1985, uma Ditadura Empresarial-Militar, "que estava a serviço do grande capital” (BORTONE, 2016, p. 79).

O empresariado que havia estimulado a investir no Brasil desde a política desenvolvimentista do governo de Juscelino Kubitschek, a partir da década de 1950, pretendia expandir seus domínios, mediante ações estatais que favorecessem a consecução de seus objetivos econômicos e políticos. Consolidado o golpe, representantes do Instituto de Pesquisas e Estudos Sociais (IPES) ocuparam cargos importantes no governo e estabeleceram o domínio do capital internacional nas esferas do poder.

A deflagração do golpe e a manutenção dos militares no poder foram sustentadas pela Doutrina de Segurança Nacional. Concebida nos Estados Unidos, no período da Guerra Fria, a concepção da Doutrina de Segurança Nacional era pautada na defesa da ordem social e no fortalecimento do Estado para o combate contra as forças comunistas. No Brasil, a tarefa de implantação da Doutrina de Segurança Nacional foi assumida pela Escola Superior de Guerra.

Na sequência ao golpe, ocorrido em março de 1964, os militares agiram, imediatamente, no intuito de estender as deliberações do novo governo para todo o território nacional, garantindo com que estados e municípios reconhecessem o poder recém-estabelecido e cumprissem as determinações impostas pelo novo governo. 
O estado da Bahia era governado, no período da implantação da ditadura, por Lomanto Júnior, que havia sido eleito governador nas eleições de 1962. Na conjuntura que antecedeu ao golpe, o governador da Bahia estava aliado a João Goulart (Jango), por meio do qual buscava conseguir apoio financeiro governo federal para investimentos na tentativa de modernização do estado. Logo após o golpe de 64, declarou apoio a Jango no poder e, de acordo com Muniz Ferreira (2004), ainda tentou articular um movimento de defesa do mandato do presidente do Brasil, reunindo-se com sindicalistas nas dependências do Jornal da Bahia.

No entanto, com acirramento dos embates políticos, pressionando a aderir ao novo regime político e ameaçado de destituição do cargo, Lomanto Júnior manifestou apoio às Forças Armadas. Dessa forma, se manteve na função, surpreendendo a todos os que acreditavam na sua deposição. A caçada aos opositores políticos iniciou-se em todo o estado. O prefeito de Salvador, Virgildásio Sena, foi preso e "o general Manoel Mendes Pereira, no comando militar da Bahia, enviou tropas aos municípios do interior para cumprir a missão de 'sanear' as prefeituras e câmaras municipais” (DIAS, 2016, p. 44).

Os jornais noticiaram numerosas manifestações, advindas de várias instituições e agremiações, que aprovaram a deposição do presidente João Goulart, cumprimentaram as "gloriosas Forças Armadas" e manifestaram total apoio ao golpe (ZACHARIADHES, 2009). O jornal Diário de Notícias, por exemplo, anunciou, na edição de 3 de abril de 1964, que "Livre do domínio comunista, o Brasil tem, desde ontem, governo democrático". Em relação ao governo de João Goulart, a notícia enfatizava: "Aliviada, a Nação respira outra vez o ar puro da liberdade [...] após a demorada e perigosa intoxicação vermelha"; e exclamava: "Em tal ambiente não se espera da Bahia e dos baianos senão o caminho de suas melhores tradições, de seus mais elevados sentimentos, do seu patriotismo” (PINHEIRO, 2017, p. 44).

Assim como em outros estados do país, na Bahia a demonstração de apoio aos militares partiu tanto dos veículos de comunicação e informação quanto de parte da população que, tomada por um intenso sentimento anticomunista, ocupou as ruas em sinal de consentimento e contentamento pelo governo que representava, na visão de muitos civis, a libertação do país de uma praga que ameaçava destruir a tão valorosa moral sobre a qual se pautava a família brasileira.

Em publicação sobre a participação feminina nos movimentos de concordância ao novo regime, Ediane Santana (2009) mostrou como as mulheres soteropolitanas de classe média se articularam na tarefa de demonstração popular de apoio ao golpe e contra o comunismo. "Do ponto de vista ideológico, além da influência do conservadorismo cristão, do discurso anticomunista e do comprometimento com seus interesses de classe, as mulheres exerciam seus papéis fundamentados pelo discurso do 'Maternalismo"' (SANTANA, 2009, p. 21).

As "marchas das mulheres" proclamavam a construção social de gênero, reafirmando os papéis atribuídos a homens e mulheres na sociedade. Manifestações de mulheres na qualidade de mães e donas de casa são aceitáveis socialmente, pois se constituem em intervenções públicas que se apoiam em suas funções tradicionais, "e aí tudo vai bem. [...] Tudo se complica quando ousam agir como homens. A fronteira do político se revela particularmente resistente" (PERROT, 2007, p. 146). 
A movimentação de teor anticomunista possibilitou a inserção de diversas mulheres nos espaços públicos, trazendo significativa notoriedade para algumas delas. Contando com o expressivo apoio da deputada estadual Ana Oliveira, primeira mulher a presidir uma sessão da Assembleia Legislativa do Estado da Bahia, as mulheres soteropolitanas se organizaram e realizaram a maior manifestação baiana de apoio aos militares, a "Marcha da Família, com Deus, pela Democracia", realizada em 15 de abril de 1964, da qual estimou-se a participação de cerca de 400 mil pessoas.

Foi a partir desse evento que surgiu a União Cívica Feminina (UCF), em Salvador, que firmou o compromisso feminino com a luta contra a infiltração comunista no país (SANTANA, 2009). Nesse contexto, destacou-se o engajamento da primeira-dama do estado, Hildete Lomanto, que obteve papel de destaque na imprensa, saindo de um cenário de invisibilidade política para a liderança das mobilizações e da própria presidência da UCF. Depois do sucesso que representou a marcha em Salvador, outros municípios baianos também realizaram o evento para saudar a ditadura.

$\mathrm{Na}$ perspectiva de que nenhum conteúdo é neutro e de que nenhuma proposta pedagógica está isenta de intencionalidade, os/as professores podem empregar textos, documentos e fontes diversas relativas ao período da Ditadura Empresarial Militar, sob a ótica regional. Com o intuito de contribuir na formação de cidadãos/ãs críticos/as, autônomos/as, capazes de compreender a realidade, situar-se nela e partir em busca de sua transformação, os/as professores/as devem desafiar os/as estudantes a colocar em prática os conhecimentos adquiridos na escola.

As expor, para o público escolar, as trajetórias de mulheres que participaram das lutas contra a ditadura, o/a professor/a deve criar espaços para problematizações e discussões que podem permitir a construção de uma aprendizagem pautada na valorização do conhecimento histórico, no reconhecimento de múltiplos sujeitos e no respeito às diferenças, de maneira que os conhecimentos adquiridos possam fazer diferença na vida dos/as estudantes.

\section{EM CENA, VITÓRIA DA CONQUISTA NO CONTEXTO DO GOLPE DE 1964}

Vitória da Conquista está localizada na mesorregião Centro-Sul da Bahia, distante $509 \mathrm{~km}$ da capital do estado, Salvador. No contexto que se seguiu ao Golpe de 1964 o município se destacou "como centro de oposição à ditadura militar e aos seus representantes no estado da Bahia”. Por essa razão foram detidos, pelos agentes da repressão estatal, além do prefeito, "cidadãos com atuação ou suposta atuação política identificada com o governo deposto e organizações de esquerda” (SOUZA, 2010, p. 13 e 118).

Historicamente, a disputa pelo controle do poder público no município envolvia os membros da elite local, composta por latifundiários, desde o período da ocupação do território por João Gonçalves da Costa, no período Imperial Vila da Vitória ao longo do período republicano.

José Pedral, eleito nas eleições de 1962, concordava com a política reformista defendida por João Goulart. No plano local, pretendia promover reformas econômicas e sociais que pudessem inserir Vitória da Conquista no contexto da modernização capitalista. O próprio Jango esteve presente no 
município, em ato de inauguração da rodovia que liga Salvador ao Rio de Janeiro e prometeu apoio ao prefeito conquistense.

A associação de José Pedral com o projeto reformista projetado pelo governo federal, associada com os conflitos locais pelo poder, pode ser tomada como explicação para a sua deposição do cargo de prefeito, bem como a sua cassação e a suspensão de seus direitos políticos, após a consumação do golpe de 64. Juntamente com Pedral foram presas dezenas de pessoas, ao que consta na bibliografia consultada, todos homens, entre políticos, estudantes, jornalistas e comerciantes ligados ao grupo de sustentação do prefeito. O executivo foi assumido pelo presidente do legislativo, Orlando Leite.

Em entrevista a José Dias (2009), José Pedral relatou a humilhação sofrida, com a cidade ocupada por cem homens do exército, que foram à sua residência anunciar voz de prisão. Contou que, detido, ficou cerca de 48 horas incomunicável e sem alimentação. Dias aborda as experiências de medo, constrangimento e violência às quais foram submetidos os presos conquistenses. Essa violência resultou, inclusive, na morte de Péricles Gusmão Régis, liderança do prefeito no legislativo municipal, que foi encontrado na cela com os pulsos cortados. Como salienta Dias (2009, p. 87), "a experiência da interiorização da repressão após o golpe de 1964 na cidade de Vitória da Conquista, embora com suas especificidades, não difere muito do que ocorreu em outros municípios".

As particularidades das disputas locais foram potencializadas pela difusão do sentimento anticomunista. Após a deflagração do golpe, os setores conservadores e reacionários, em todo o país, assumiram o controle do poder. Assiste-se à ascensão de uma elite política que age em consonância e totalmente integrada às estratégias do governo ditatorial. Nesse contexto, "a adesão dos políticos da capital e do interior ao bloco do poder na Bahia e à classe dirigente nacional foi muito além da necessidade de acumulação econômica, de estabilidade política ou da viabilidade institucional, se vistas de forma compartimentada" (DIAS, 2016, p. 76).

No âmbito das políticas de preservação de memória e reparação do passado traumático, o município de Vitória da Conquista dispõe de um monumento, edificado em 1998, nomeado "Aos 27 Baianos Mortos e Desaparecidos Políticos, Vítimas da Ditadura Militar", que pode ser tomado como gatilho para o desenvolvimento de reflexões, nas aulas de história, sobre as lutas de mulheres contra o governo ditatorial e sobre as políticas de preservação da memória da ditadura, em âmbito local.

Memória não é o mesmo que história. As memórias "precisam ser evocadas e recuperadas e merecem ser confrontadas. [...] Nenhuma memória, individual ou coletiva, constitui a história" (BITTENCOURT, 2008, p. 170). A história, por outro lado, como destaca Le Goff (apud BITTENCOURT, 2008, p. 170), “consiste na escolha e construção de um objeto, operação que pode dar-se a partir de evocação de lembranças”. Sobre o conceito de memória, expõe Nora (1993, p. 9):

A memória é a vida, sempre carregada por grupos vivos e, nesse sentido, ela está em permanente evolução, aberta à dialética da lembrança e do esquecimento, inconsciente de suas deformações sucessivas, vulnerável a todos os usos e manipulações, susceptível de longas latências e de repentinas revitalizações. [...] A memória é um fenômeno sempre atual, um elo vivido no eterno presente. [...] A 
memória não se acomoda a detalhes que a confortam; ela se alimenta de lembranças vagas, telescópicas, globais ou flutuantes, particulares ou simbólicas, sensível a todas as transferências, cenas, censuras ou projeções. [...] Ela é por natureza, múltipla e desacelerada, coletiva, plural e individualizada. [...] A memória se enraíza no concreto, no gesto, na imagem, no objeto.

De acordo com Halbwachs (2013), nenhuma lembrança pode existir individualmente, uma vez que os contextos sociais são a base para a atividade de reconstrução da memória; portanto, a memória é coletiva. Levando em consideração que toda memória é seletiva, o esquecimento e o silêncio estão totalmente imbricados com o fenômeno de rememoração, e esses fatores estão relacionados aos usos políticos que fazemos da memória.

Constantemente ressignificada à luz das demandas do presente, a materialização da rememoração é realizada por meio dos "lugares de memória", na perspectiva de Pierre Nora, sendo eles de ordem material, simbólica e funcional:

Os lugares de memória nascem e vivem do sentimento que não há memória espontânea, que é preciso criar arquivos, que é preciso manter aniversários, organizar celebrações, pronunciar elogios fúnebres, notariar atas, porque essas operações não são naturais. É por isso a defesa, pelas minorias, de uma memória refugiada sobre focos privilegiados. (NORA, 1993, p. 13)

A história oficial da Ditadura-Empresarial Militar privilegiou a reconstituição do passado de acordo com a ótica dos vencedores, ocasionando embates, tanto pelas memórias produzidas pelo Estado, quanto pelas "memórias subterrâneas"3 (POLLAK, 1989), associadas aos movimentos sociais, que lutam para que os grupos de resistência à ditadura, dantes silenciados, possam ter suas experiências traumáticas propagadas.

Nesse contexto de disputas de memórias, Joana D’Arc Ferraz (2007) questionou a política oficial de preservação da memória da Ditadura Empresarial-Militar no Brasil, destacando que não há interesse estatal em difundir as experiências de resistência de pessoas que militaram contra a ditadura em nosso país. As iniciativas que tivemos, nesse sentido, referem-se a algumas atitudes pontuais, de representantes do poder público e de algumas prefeituras, associadas a grupos defensores dos direitos humanos.

O primeiro memorial do tipo monumento/antimonumento construído em homenagem aos mortos e desaparecidos no Brasil data do ano de 1993, e foi edificado na cidade de Recife. Trata-se da construção monumental/antimonumental "Tortura Nunca Mais", cuja construção insere-se no contexto de políticas de memória empreendidas com vistas à reparação simbólica das vítimas do período ditatorial.

O conceito de antimonumento refere-se às construções contrárias ao monumento tradicional, pois possuem outra finalidade, utilizando-se de uma estética diferenciada, como explica Benjamin (apud TAVARES, 2021, p. 7).

Enquanto o monumento tradicional, desde a Antiguidade, esteve ligado mais a celebrar (heróis, feitos heroicos), a comemorar (vitórias bélicas), do que a ideia de advertir, o antimonumento pertence a outra orientação política e ideológica, ou seja,

\footnotetext{
${ }^{3}$ Conceito que se refere às memórias marginalizadas, clandestinas e inaudíveis, representadas por grupos sociais dominados.
} 
é erigido para lamentar a dor e o sofrimento das vítimas de uma tragédia; pertence à tradição da "história dos vencidos", uma história a contrapelo.

Desde a construção do memorial "Tortura Nunca Mais", em Recife, outros monumentos/antimonumentos foram erigidos pelo Brasil, como é o caso do "Aos 27 baianos mortos e desaparecidos políticos, vítimas da Ditadura Militar”, em Vitória da Conquista. Inaugurado em 9 de julho de 1998, sob a gestão do prefeito Guilherme Menezes, o memorial, de iniciativa do Grupo Labor Assessoria, Documentação e Pesquisa, está localizado na Praça Tancredo Neves, no centro da cidade. Explica Tavares (2021, p. 11):

A obra escultórica deve sua concepção artístico/ideológica aos artistas plásticos conquistenses Ana Palmira Bittencourt Santos Casimiro e Romeu Ferreira Filho (a arte deste, com supervisão daquela), conjuntamente com o prof. Ruy Hermann Araújo Medeiros [ex-preso político no período ditatorial]. Sua construção contou com recursos públicos através de subscrições populares.

A construção monumental/antimonumental é constituída por duas grandes placas de metal. Em uma delas, na parte externa, é sobreposta uma outra placa, na qual foram inscritos 27 nomes de pessoas baianas, vítimas da violência institucional empreendida pela Ditadura Empresarial-Militar. ${ }^{4}$ Dos vinte e sete nomes relacionados na placa, três referem-se a mulheres: Dinaelza Santana Coqueiro, Dinalva Oliveira Teixeira e Nilda Carvalho Cunha.

Na placa grande há uma figura vazada no centro, no formato de um ser humano, "denunciando simbolicamente a dualidade presença/ausência de vários mortos e desaparecidos pela violência da ditadura" (TAVARES, 2021, p. 12), como pode ser observado na figura 1

Na parte interna, uma placa menor, contém a designação do monumento/antimonumento, local, data da construção e os créditos aos responsáveis pela elaboração e construção da obra. ${ }^{5} \mathrm{Na}$ placa há, ainda, a inscrição de um pensamento de José Saramago; “Aprendamos um pouco, isso e o resto, o próprio orgulho também, com aqueles que do chão se levantaram e a ele não tornam, porque do chão só devemos querer o alimento e aceitar a sepultura, nunca a resignação".

\footnotetext{
${ }^{4}$ Seguem os nomes dos/as 27 baianos/as, mortos/as e/ou desaparecidos/as inscritos no monumento/antimonumento em Vitória da Conquista: Antônio Carlos Monteiro Teixeira, Aderval Alves Coqueiro, Carlos Marighella, Demerval da Silva Pereira, Dinaelza Santana Coqueiro, Dinalva Oliveira Teixeira, Eudaldo Gomes da Silva, Jorge Leal Gonçalves, José Lima Piauhy Dourado, João Carlos Cavalcante Reis, José Campos Barreto, Joel Vasconcelos Santos, Luís Antônio Santa Bárbara, Mário Alves de Sousa Vieira, Maurício Grabois, Nilda Carvalho Cunha, Nelson Lima Piauhy Dourado, Péricles Gusmão Régis, Pedro Domiense de Oliveira, Otoniel Campos Barreto, Rosalindo Sousa, Sérgio Landulfo Furtado, Stuart Edgard Angel Jones, Uirassu de Assis Batista, Vitorino Alves Moitinho, Vandick Reidner Pereira Coqueiro, Walter Ribeiro Novaes. ${ }^{5} \mathrm{O}$ monumento/antimonumento, foi realizado por inciativa do Labor, com arte de Romeu Ferreira e supervisão de Ana Palmira Casimiro. A execução ficou por conta de Moisés Rodrigues da Silva e Marcionílio Alves Costa, em oficina da Marmoraria Amsterdã.
} 
Figura 1 - Monumento/antimonumento "Aos 27 baianos mortos e desaparecidos políticos, vítimas da Ditadura Militar”, edificado na Praça Tancredo Neves, em Vitória da Conquista-Ba

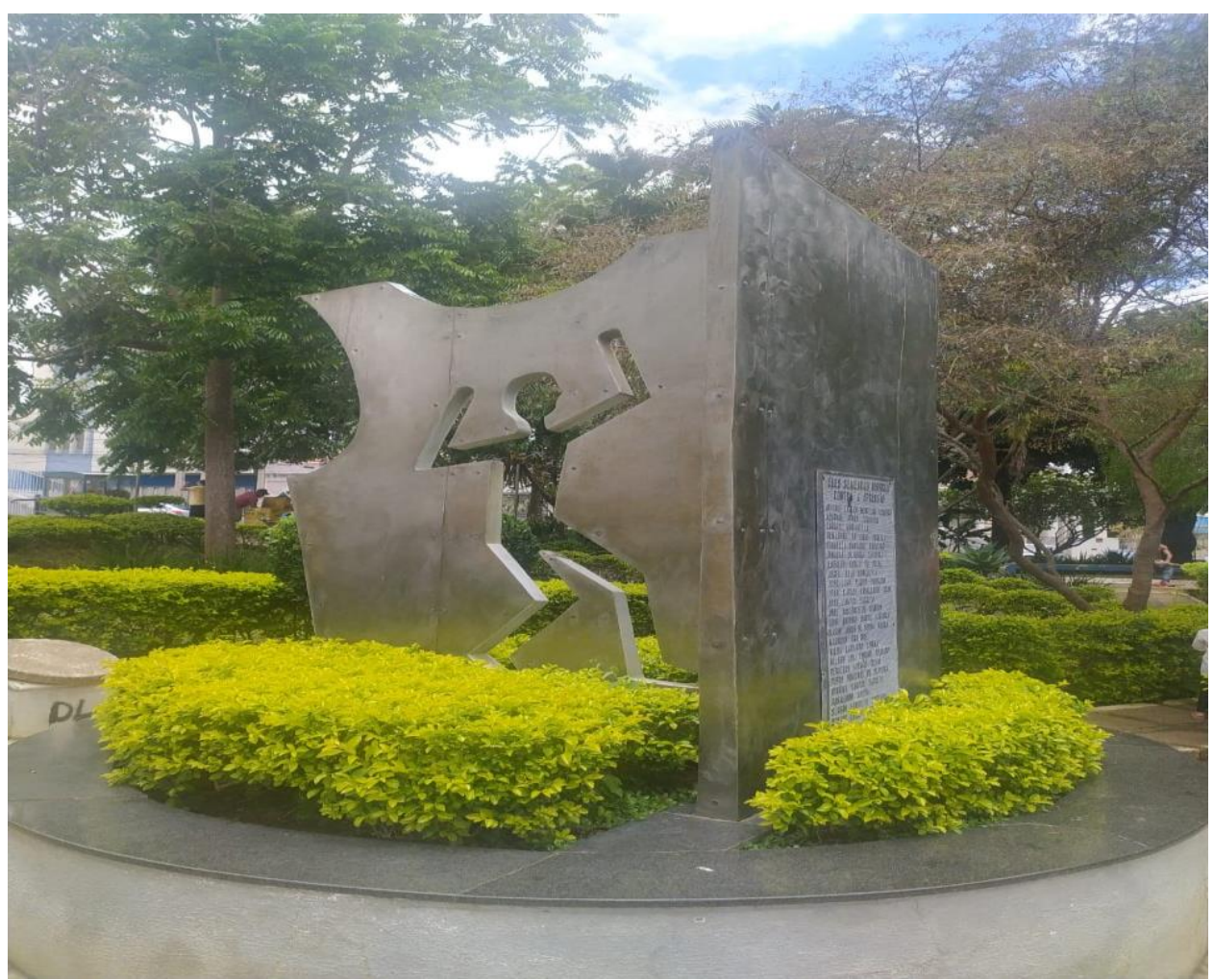

Fonte: Acervo da autora (2021).

Os esquecimentos e silêncios, em relação aos/às mortos/as e desaparecidos/as por ação da ditadura, ao serem transformados em memória social reforçam a cobrança por reparação jurídica e moral e a luta por justiça e pela verdade. Levar essa temática para a sala de aula, no entrelaçamento entre memória e história local "tem sido indicada como necessária para o ensino por possibilitar a compreensão do entorno do aluno, identificando o passado sempre presente nos espaços de convivência e igualmente por situar os problemas significativos da história do presente" (BITTENCOURT, 2008, p. 168).

A problematização em sala de aula do monumento/antimonumento "Aos 27 baianos mortos e desaparecidos políticos, vítimas da Ditadura Militar”, possibilita discutir questões relacionadas ao intuito e aos sentidos do memorial e refletir sobre os significados dessa construção para a população. Pode, ainda, proporcionar aos/as estudantes, o conhecimento sobre as especificidades e multiplicidades da história na região em que vivem, pode ajudar-lhes a pensar as relações dialéticas entre o todo e a parte, além de valorizar a memória, o patrimônio cultural e a noção de pertencimento a partir das experiências das “memórias subterrâneas”. Como salientam Zarbato e Santos (2015, p. 70),

O ensino da história local, a partir do estudo do patrimônio cultural pode, assentarse nas diversas memórias disseminadas nos mais diferenciados sujeitos sociais para que se possa apreender delas as diversas versões e olhares que a experiência histórica local se fundamenta e se constitui, não devendo, sob pena de cair na homogeneidade histórica concebida pela concepção "oficial" de memória e história e tão cara às 
gerações de nossos pais, está alicerçada na visão dominante de apenas um segmento da sociedade ou de determinados indivíduos que tomaram para si a alcunha de "autênticos repositórios" da memória social.

Três nomes de mulheres constam na placa do monumento/antimonumento "Aos 27 Baianos Mortos e Desaparecidos Políticos, Vítimas da Ditadura Militar". Enfatizamos a história de luta de Dinaelza Coqueiro, nascida na cidade de Vitória da Conquista, cuja trajetória de vida está interligada com as lutas de sua irmã, Diva Santana. Conhecer os percursos de lutas dessas mulheres é fundamental para que histórias de resistência feminina à opressão ditatorial sejam levadas ao conhecimento do público escolar, mediante o rompimento com a invisibilidade das atuações desses sujeitos na historiografia.

\section{AS TRAJETÓRIAS DE LUTAS DE DINAELZA COQUEIRO E DIVA SANTANA}

Dinaelza Soares Santana nasceu em 22 de março de 1949, no Distrito de São Sebastião, município de Vitória da Conquista. Era filha de Junília Soares Santana e Antônio Pereira de Santana. Em 1957, a família Santana migrou para a cidade de Jequié. Depois de concluído o Curso Normal, em Jequié, Dinaelza mudou-se para Salvador, prestou vestibular para Geografia na Universidade Católica de Salvador, obtendo a aprovação.

$\mathrm{Na}$ capital baiana, Dinaelza se dedicou aos estudos, conseguiu um emprego e se engajou na militância do movimento estudantil universitário. Ela conheceu seu futuro marido, Vandick, em Jequié, se reencontraram em Salvador e com pouco tempo de namoro resolveram se casar. Casaram-se em 25 de abril de 1970, quando Dinaelza Santana passou a ser Dinaelza Coqueiro. O casal morou em um apartamento presenteado pelo pai do noivo por um pequeno período, mas, com a militância, passaram a viver em constante deslocamento, em "aparelhos" definidos pelo movimento.

Nos anos iniciais da Ditadura, o PC do B direcionou a ação política da militância nas grandes cidades e buscou adeptos no movimento estudantil, reorganizando entidades extintas, como a União dos Estudantes da Bahia (UEB) e a Associação Baiana dos Estudantes Secundaristas (ABES). O partido via no segmento estudantil uma grande possibilidade de recrutamento de militantes capacitados para lutar contra o regime ditatorial.

O partido desenvolvia suas atividades de forma a conquistar novos adeptos e a fortalecer o movimento dos estudantes, realizando propaganda política, panfletagem e comícios relâmpagos, todas atividades clandestinas. Aliando-se às ideias do PC do B, Dinaelza acreditava que a guerra popular era o único caminho para a derrubada da ditadura instaurada no país. Com esse objetivo, ela e o marido, imersos completamente na militância, adquiriram posição de destaque na organização partidária.

Entre o final de março e o início de abril de 1971, o casal de militantes teve que partir de Salvador em virtude do iminente perigo de prisão. Foi, então, deslocado pelo partido para a realização de um trabalho especial, diferenciado. Havia segredo em relação à tarefa e ao local onde seria realizada; portanto, Dinaelza e Vandick foram solicitados sem saber para onde iriam e o que fariam. 
A movimentação de homens e mulheres para levar a cabo confrontos armados contra a ditadura remonstava ao ano de 1965. Em 1971, escolhido pelo PC do B para integrar um grupo de guerrilheiros/as que se prepararia para uma luta armada. o casal Coqueiro foi deslocado para a região conhecida como "Bico do Papagaio", que compreendia a tríplice fronteira dos estados do Piauí, Maranhão e Goiás.

Lima explica a escolha da região do Araguaia como campo para a deflagração do confronto: “as condições geográficas, a existência da floresta e dos rios, as condições de vida da população foram decisivas para que a região fosse eleita pelo Partido" (LIMA, 2019, p. 61). A população do Araguaia vivia em completo abandono pelo poder público. Sem acesso à saúde e educação, estava a mercê dos grandes fazendeiros, que exploravam os trabalhadores em condições análogas à escravidão.

Entre os anos de 1969 e 1972, sessenta e nove combatentes chegaram à localidade do Araguaia para iniciar a organização da guerrilha, sendo que, desse total, 10 militantes eram do estado da Bahia. Dentre os baianos que se apresentaram para o combate estavam Mariadina ou Diná e João ou João Goiano, como passaram a ser chamados Dinaelza e Vandick.

Três campanhas foram empreendidas pelas Forças Armadas contra o movimento de guerrilha. Embora os militares possuíem muito mais recursos, tanto materiais quanto humanos, em junho de 1972 deixaram a região. Dois meses depois, voltaram com mais soldados e com a estratégia de obter a simpatia da população, com a finalidade de isolar os guerrilheiros e obter uma vitória rápida. Mais uma vez, não obtiveram sucesso. A terceira campanha foi devastadora, com a ocupação ostensiva da localidade, bem como das áreas ao redor, colocando um ponto final à guerrilha de maneira extremamente violenta. No final de dezembro de 1973 os comandantes dos destacamentos das forças guerrilheiras foram mortos. Estava decretado o fim da guerrilha do Araguaia. A partir de então, os sobreviventes saíram sem rumo pela mata. Testemunhas relataram que Dinaelza Coqueiro e seu companheiro ainda resistiram, fugindo pela mata, por algum tempo, até serem encontrados pelas Forças Armadas e mortos. Os militares empreenderam esforços para não deixar vestígios sobre o confronto, por isso os corpos não foram encontrados até hoje.

Nesse novo contexto, emerge a figura da mulher militante Diva Santana. Nascida em 1949, em Vitória da Conquista, Diva Santana era a mais velha de cinco irmãos. Casou-se bastante jovem, em 1964, com apenas 15 anos de idade. Divorciou-se e casou-se novamente em 1971. Ficou viúva quando tinha somente 32 anos. Teve três filhos. Envolveu-se em movimentos de oposição à ditadura a partir da segunda metade da década de 70, em busca de respostas sobre o desaparecimento de sua irmã, Dinaelza. Em 1976, ingressou no Comitê Baiano pela Anistia (CBA).

Na luta em busca da verdade sobre o desaparecimento de Dinaelza, Diva Santana seguiu para a região do Araguaia, em 1980, juntamente com outros familiares de desaparecidos/as políticos/as. Nessa viagem com a caravana, Diva foi informada por moradores da localidade que Dinaelza havia sido morta em combate.

Familiares dos/as desaparecidos/as políticos/as envolvidos/as no conflito do Araguaia encontraram, e encontram, muitas dificuldades em relação à busca de pistas sobre o paradeiro dos/as 
militantes. Não houve inquéritos pelos órgãos repressores e documentos das Forças Armadas envolvendo os/as guerrilheiros/as foram destruídos. O governo ditatorial não admitiu a morte dos/as militantes na guerrilha e não revelou onde estão os corpos. A busca de respostas sobre os fatos ocorridos no confronto exige resistência e persistência e é fundamental para que a população brasileira tenha conhecimento do que foi a guerrilha, para que os fatos não caiam no esquecimento. A resistência produziu inúmeros documentos sobre o conflito com o intuito de impedir que o Estado ditatorial promovesse o silenciamento e apagamento desse importante episódio da história do país, mas os seus militantes foram alvo de ação estatal.

Diva Santana revela que, por conta de sua insistência em revelar a veracidade dos fatos ocultados pela ditadura, sofreu ameaças anônimas de morte e perseguições dos agentes de repressão. Movida pelo direito à memória de sua irmã, Diva se engaja na militância política. Sua resistência ficou demonstrada pela participação em atos de protesto, de denúncia e na promoção de ações por justiça e pela verdade. Atualmente, ela participa do grupo “Tortura Nunca Mais”. Na Bahia, essa organização, fundada em 1995, visa a promoção e a defesa dos direitos humanos em prol da justiça de diversos grupos sociais.

Diva Santana passou a desempenhar um papel significativo na busca por rastros dos/as desaparecidos/as políticos/as. Juntou-se a outros familiares de vítimas da ditadura, que, entre as várias ações promovidas para pressionar o Estado a revelar a verdade, elaboraram o livro "Dossiê dos Mortos e Desaparecidos Políticos" e participaram do II Congresso Brasileiro de Anistia.

As lutas sustentadas pelos familiares das vítimas e por entidades em defesa dos direitos estão na base das políticas tardias de memória e reparação por parte do Estado em relação aos/às mortos/as e desaparecidos/as no período da Ditadura Empresarial-Militar. Foram essas lutas que permitiram que eventos ocorridos durante o período ditatorial não caíssem no esquecimento.

O relatório da "Comissão Nacional da Verdade" reconhece a condição de desaparecida política de Dinaelza Coqueiro e levanta a questão sobre da morte de militantes cujos restos mortais não foram entregues à família com o fim da realização de um sepultamento digno. Por existirem inconclusões nas investigações, o relatório recomenda que estas devem prosseguir em busca da verdade para que a justiça seja feita.

A militante Diva Santana, em sua racionalidade, reconhece o desaparecimento da irmã e crê em sua morte, pois os relatos de moradores do Araguaia confirmam essa hipótese. No entanto, quando os sentimentos e as emoções falam mais alto, sobressai a esperança de que sua irmã esteja viva: o fato de que os restos mortais não tenham sido encontrados pode significar que a morte dela não tenha acontecido. É com essa mistura de emoções que todos os familiares de Dinaelza convivem, desde o seu desaparecimento.

Assim, as lutas de resistência contra a ditadura travadas por Dinaelza foram perpassados a seus familiares, principalmente Diva, que ainda procura fazer com que as verdades relativas ao desaparecimento de sua irmã sejam reveladas. A busca por um corpo insepulto faz com que as dores dos familiares se arrastem pelos tempos. A batalha pela verdade é, também, luta por justiça, para que os 
responsáveis pelos crimes cometidos em nome do Estado sejam responsabilizados, culpabilizados e punidos.

Dentre tantas palavras que podem caracterizar o percurso de vivências das duas histórias das mulheres aqui elencadas, a expressão coragem denota as existências e atitudes experienciadas por elas, cujas escolhas as levaram a batalhar, duplamente, contra a Ditadura Empresarial-Militar e contra as concepções sexistas da sociedade. Invisibilizadas na historiografia, as atuações políticas de Dinaelza Coqueiro e Diva Santana e tantas outras militantes devem ser levadas ao conhecimento do público escolar para serem reconhecidas em seus papéis de sujeitos da História.

\section{CONSIDERAÇÕES FINAIS}

Análises de livros didáticos de História, utilizados pelo público da Educação Básica, reforçam a assertiva de que as mulheres não estão presentes nesses materiais que, muitas vezes, são os maiores aliados (às vezes os únicos) do trabalho do/a professor/a em sala de aula. Quando algum aspecto da história das mulheres aparece nos manuais didáticos, geralmente, é no fim da página, ou em caixa de texto, desvinculado da narrativa principal.

Essa negligência é consequência da ausência das mulheres na produção historiográfica, até meados do século XX. Os registros históricos foram realizados, majoritariamente, por historiadores, homens que não reconheciam as vivências femininas como dignas de ser perpetuadas em suas narrativas. É esse o quadro consubstancia a ausência de mulheres nos relatos de lutas de resistência à Ditadura no Brasil. Divulgar as trajetórias de mulheres que resistiram à violência institucional e de gênero ao público da Educação Básica pode se constituir em importante estratégia para retirar as mulheres da penumbra dos registros históricos, conferindo a essas mulheres visibilidade e reconhecimento em seus papéis de protagonistas da história.

Consideramos que a escola seja um instrumento capaz de possibilitar os mecanismos para que as classes populares possam ser capazes de transformar a sociedade. Estabelecendo uma relação dialética com a sociedade, a educação se constitui em instrumento de mediação da prática social e deve promover a mobilização dos sujeitos para a modificação da realidade a partir da aquisição de conhecimentos teóricos. O estudo das experiências das mulheres militantes, articulado com problematizações em relação às políticas de reparação de eventos traumáticos empreendidas nos espaços locais, pode viabilizar que docentes e discentes articulem teoria e prática, tornando-se agentes ativos no processo de transformação das relações sociais.

Há esforços significativos, nas universidades, para a reconstrução de memórias das mulheres militantes, o que tem resultado no aumento da produção acadêmica sobre o tema. Enfatizamos a importância e expressividade de trabalhos acadêmicos voltados para o atendimento das demandas da Educação Básica. É o caso das pesquisas desenvolvidas no âmbito do Mestrado Profissional em Ensino de História. A proposição de novas formas de abordagens didáticas indica um potencial para romper com a invisibilização das mulheres que se destacaram no enfrentamento à repressão e nas lutas pela 
democracia. A difusão desses estudos, além de contribuir para a consolidação da dialética do conhecimento entre todo-parte, pode contribuir para que os/as estudantes venham a se reconhecer enquanto agentes ativos/as no processo de transformação das relações sociais.

\section{REFERÊNCIAS}

BITTENCOURT, C. M. Ensino de História: fundamentos e métodos. São Paulo: Cortez, 2008.

BORGES, N. A Doutrina de Segurança Nacional e os governos militares. In: FERREIRA, J.; DELGADO, L. A. N. (org.). O Brasil Republicano, v. 4: o tempo da ditadura - regime militar e movimentos sociais em fins do século XX. Rio de Janeiro: Civilização Brasileira, 2014. p. 13-42.

BORTONE, E. de A. A presença de empresários do Instituto de Pesquisas e Estudos Sociais (IPES) nas empresas estatais federais: o caso do setor financeiro (1964-1967). In: PICCOLO, M. (org.). Ditaduras e democracias no mundo contemporâneo: rupturas e continuidades. São Luís: Ed. da UEMA, 2016. p. 73-101

CALIL, G. Uma História para o conformismo e a exaltação patriótica: crítica à proposta de BNCC/História. Giramundo, Rio de Janeiro, v. 2, n. 4, p. 39-46, jul./dez. 2015.

COLLING, A. M. A resistência da mulher à ditadura militar no Brasil. Rio de Janeiro: Rosa dos Tempos, 1997.

DIAS, J. A. O golpe de 1964 e as dimensões da repressão em Vitória da Conquista. In: ZACHARIADHES, G. C. (Org.). Ditadura Militar na Babia: novos olhares, novos objetos, novos horizontes. Salvador: Edufba, 2009. p. 69-88

DIAS, J. A. Rumo ao Palácio: as estratégias de dominação dos espaços políticos na Bahia durante a ditadura (1966-1982). Vitória da Conquista: Edições Uesb, 2016.

FERRAZ, J. D’A. F. As Memórias Políticas da Ditadura Militar do Brasil: as disputas entre o passado e o futuro. In: ABREU, R.; CHAGAS, M. de S.; SANTOS, M. S. dos. (org.). Museus, coleções e patrimônios: narrativas polifônicas. Rio de Janeiro: Garamound; MinC/IPHAN/DEMU, 2007. p.48-67.

FONSECA, S. G. Didática e prática de Ensino de História. São Paulo: Papirus, 2009.

GASPAROTTOT, A; BAUER, C. S. O ensino de História e os usos do passado: a ditadura civil-militar em sala de aula. In: ANDRADE, J.; PEREIRA, N. M. Ensino de História e suas práticas de pesquisa. (org.) São Leopoldo: Oikos, 2021. Disponível em: https://lume.ufrgs.br/bitstream/handle/10183/220721/001125511.pdf. Acesso em: 17 de julho de 2021.

GERMINARI, G. Educação Histórica: a constituição de um campo de pesquisa. Revista HISTEDBR, Campinas, n. 42, p. 54-70, jun. 2011. Disponível em:

https://periodicos.sbu.unicamp.br/ojs/index.php/histedbr/article/view/8639866/7429. Acesso em: 10 de julho de 2021.

GONÇALVES, R. de C. O passado e a história difícil para o ensino e aprendizagem da História. Antíteses, v. 11, n. 22, p. 559-581, jul./dez. 2018.

HALBWACHS, M. A memória coletiva. São Paulo: Centauro, 2013. 
JOFFILY, O. R. Esperança Equilibrista: resistência feminina à Ditadura Militar No Brasil (1964-1985). 2005. Tese (Doutorado em Ciências Sociais) - Pontifícia Universidade Católica de São Paulo, São Paulo, 2005.

LIMA, G. de O. P. Do corpo insepulto à luta por Memória, Verdade e Justiça: Um estudo do caso Dinaelza Coqueiro. Tese (Doutorado em Memória: Linguagem e Sociedade) - Universidade Estadual do Sudoeste da Bahia, Vitória da Conquista, 2019.

MACHADO, V. Memória e livros didáticos: as mulheres contra a ditadura. In: ENCONTRO NACIONAL DE HISTÓRIA ORAL, 10., Pernambuco, UFPE, 2010. Disponível em: https://encontro2010.historiaoral.org.br/resource/anais/2/1270416340_ARQUIVO_pdf. Acesso em: 08 de abril de 2021.

NORA, P. Entre memória e história: a problemática dos lugares. Projeto História. São Paulo, n. 10, p. 7 28, dez. 1993.

PERROT, M. Minha história das mulheres. São Paulo: Contexto, 2007.

PINHEIRO, C. C. Estar com ele, estar com ela: memórias das esposas dos presos políticos da Penitenciária Lemos de Brito, Salvador anos de 1970. 2017. Tese (Doutorado em Estudos Interdisciplinares sobre Mulheres, Gênero e Feminismo) - Universidade Federal da Bahia, Salvador, 2017.

PINSKY, C. B. Gênero. In: PINSKY, C. B. (Org.). Novos temas nas aulas de História. São Paulo: Contexto, 2018. p. 29-54.

POLLAK, M. Memória, esquecimento e silêncio. Estudos Históricos. Rio de Janeiro, v. 2, n. 3, p. 3-15, 1989.

REIS FILHO, D. A.; FERREIRA DE SÁ, J. Imagens da Revolução: documentos políticos das organizações clandestinas de esquerda dos anos 1961 a 1971. Rio de Janeiro: Marco Zero, 1985.

RIDENTI, M. S. As mulheres na política brasileira: os anos de chumbo. Tempo Social, São Paulo, v. 2, n. 2, p. 113-128, 1990.

SANCHEZ, G. R. A Litany of White Men: The Brazilian Textbook Industry and the Reproduction of Old Canons. Thesis (Master's in Latin American studies) - University of Texas at Austin, Texas, 2017.

SANTANA, E. L. Campanha de desestabilização de Jango: as "donas" saem às ruas! In: ZACHARIADHES, G. (org.). Ditadura militar na Babia: novos olhares, novos objetos, novos horizontes. Salvador, Edufba, 2009. p. 13-29

SCOT'T, J. Gênero: uma categoria útil de análise histórica. Educação \& realidade. Porto Alegre, v. 20, n. 2 , p. 71-99, jul/dez. 1995.

SILVA, M. A. da; FONSECA, S. G. Ensino de História hoje: errâncias, conquistas e perdas. Revista Brasileira de História. São Paulo, v. 31, n. 60, p. 13-33, 2010.

SOUZA, B. de J. Uma pólis sertaneja, fora do eixo e fora do centro: imprensa e memória nas disputas políticas em Vitória da Conquista (1962-1992). 2010. Tese (Doutorado em História Social) - Universidade Federal da Bahia, Salvador, 2010.

TAVARES, D. K. Monumentos/antimonumentos no Nordeste do Brasil: história, memória e narrativas da violência da ditadura militar. ENECULT, 17., 2021, Salvador, UFBA, jul. 2021. Disponível em: https://enecult.ufba.br/modulos/submissao/Upload-568/131229.pdf. Acesso em: 10 de outubro e 2021. 
VEYNE, P. Como se escreve a história e Foucault revoluciona a história. Brasília: Ed. da UNB, 1998.

ZARBATO, J. As estratégias do uso do gênero no ensino de História: narrativa histórica e formação de professoras. Trilhas da História, Três Lagoas, v. 4, n. 8, p. 49-65, jan.-jun., 2015.

ZARBATO, J; SANTOS, C. V. dos. Memória e patrimônio na aula de história: o uso do monumento histórico-cultural na aprendizagem histórica. Fronteirass, Dourados, v. 17, n. 30, p. 64-79, jul.-dez. 2015.

Data de submissão: 23/12/2021

Data de aprovação: 30/01/2022 